\title{
Bundling Private Complements to Finance Public Goods
}

\author{
H. Spencer Banzhaf* and V. Kerry Smith**
}

\begin{abstract}
The National Park Service and other agencies argue that our recreation lands face a crisis of deferred maintenance. This paper evaluates two proposals for funding public lands, increasing gate fees and taxing recreational gear. It analyzes the joint welfare effects of such taxes and the services supported by the revenue. It shows that when the taxed goods and the public service are "weak complements," there is a simple sufficient statistic determining whether the joint effect increases welfare both for consumers and sellers: Namely, the demand for the taxed good increases. The paper illustrates these results with data for recreational services.
\end{abstract}

\section{Introduction}

The National Park Service (NPS) has argued that our national parks face a growing crisis because of their inability to address deferred maintenance needs. ${ }^{1}$ Several recent administrations have attempted to address this backlog through legislation and changes in agency rules. Nonetheless the backlog has continued to increase. By one account, the parks overall had a backlog of $\$ 11.9$ billion in FY2018 (CRS 2021). Similarly, the Bureau of Land Management (BLM), Fish and Wildlife Service (FWS), and Forest Service (FS) report deferred maintenance amounting to $\$ 7.5$ billion in 2018. Comparison of these estimates to those for earlier years (in constant dollars) suggests the problem is not new. Indeed, there have been high levels of deferred maintenance for these agencies since at least FY2009. The picture is more mixed for the state level, but there are certainly some states with significant maintenance backlogs.

Meanwhile, newly issued Executive Order 14008, under President Biden, sets a goal of conserving at least $30 \%$ of public and private lands by 2030 . It seeks new strategies for encouraging broad participation among state, local, Tribal, and territorial officials, agricultural and forest landowners, fishers, and other key stakeholders. Adding more lands will only increase the revenue

*Banzhaf: Professor, Department of Economics, Georgia State University, Atlanta; Senior Fellow, Property and Environment Research Center (PERC); Research Associate, National Bureau of Economic Research (NBER). hsbanzhaf@gsu.edu

${ }^{* *}$ Smith: Emeritus faculty, Department of Economics, Arizona State University, Tempe; Research Associate, National Bureau of Economic Research (NBER). kerry.smith@cavecreekinstitute.com.

We thank the Property and Environment Research Center (PERC) for support of this research, and attendees at a 2019 PERC workshop for valuable comments. 
needs.

There are three main strategies for meeting these revenue needs. The first is to fund public lands through general revenues. The second is to raise revenue through entrance fees, which, conceptually, can be thought of as a tax on trips to the destination. The third approach would tax equipment associated with recreation. Of course, the definition of which private goods and services are associated can be narrow or broad. Under a narrow definition, the tax might be confined to fishing rods and reels. If broad, it might be expanded to include clothing, boots, and other sports gear.

The first strategy, using general revenues, is consistent with the standard emphasis in public finance focusing on efficiency. Following Ramsey's (1927) classic paper, tax analysis would begin by asking about revenue needs and then, second, how to distribute the burden across an excise tax system based on its efficiency. The answer to this second question depends on how it distorts the relative demands for each good. From this perspective, dedicated taxes linking revenue from a particular source to a particular purpose are simply policy-motivated constraints on the problem. See Myles (1995 p. 105) for a textbook treatment and Walls (2013) and Walls and Ashenfarb (this issue) for a discussion in the context of funding parks.

However, this is also largely the status quo approach. A recent Congressional Research Service (2021) (CRS) report compares FY2021 appropriations for the NPS to those in 2020. Overall, the NPS received 8\% less in regular appropriations under PL116-260 (passed December 27,2020). While some accounts increased (notably Operations, Historic Preservation, and National Recreation and Preservation), the remaining three categories either decreased or were eliminated (see table 1 in CRS [2021]). Yet these appropriations have not addressed the maintenance backlog. ${ }^{2}$

Accordingly, in this paper, we evaluate the alternative strategies of entry fees and the gear tax. The timing of our assessment could not be better. Although neither of these policies have provided as much funding as have general revenues, both strategies have been used to some extent. In 1996, the US Congress authorized the "Fee Demonstration Program," in which certain units of the NPS, FS, BLM, and FWS could charge fees to users, with at least $80 \%$ of the revenues staying in the local unit, thereby incentivizing managers to make the most efficient use of their funds. Fees are collected at 165 NPS units (39.4\% of all units), of the 30,000 NFS developed campsites, 4,000 
(13.3\%), 400 BLM units with developed recreation (11.1\%), and 200 FWS refuges (43.5\%) (CRS 2020). Together, the agencies collected approximately $\$ 442.3 \mathrm{~m}$ in entrance fees in $2019 .{ }^{3}$ For its part, the gear tax would essentially be an extension of the Pittman-Robertson and Dingell-Johnson Acts, which authorize taxes on hunting and fishing gear to other types of recreation related equipment. These taxes generate over $\$ 1 \mathrm{~b}$ annually for conservation programs. ${ }^{4}$

Both recreation fees and the gear tax involve collecting revenue from private activitiestrips to public lands and purchases of gear, respectively - that are complements to the services provided by public lands. This complementarity has two implications. First, it has implications for the efficiency of the taxes. Complementarity creates a feedback from the increase in quality of the service supported through the new (or increased) tax revenue back onto the demand for the taxed goods. In these cases, there is the conventional direct effect of the tax, which distorts market signals, and the feedback effect of the increase in quality supported through the new (or increased) tax revenue on the demand for the taxed goods. These feedback effects are ignored by conventional treatments of optimal taxation.

Second, complementarity implies that services are being supported by taxing those who benefit from them. The benefit, or user-pay principle, suggests that those who benefit from a publicly provided good should be the ones to bear the burden of funding it. ${ }^{5}$ Taxing gasoline to fund roads and property taxes to fund local amenities are examples. Such dedicated tax systems bring the financing of public goods somewhat closer to private markets, where users generally pay for the services because they are the ones who benefit, as with private goods.

In this paper, after reviewing the economics of bundling and weak complementarity in Section 2, we analyze, in Section 3, the efficiency and distributional effects of increasing, jointly, a gate fee and enhancing the quality or amount of a public good that is funded by the fee revenues. To simplify the analysis, we first assume trips to public lands are "weak complements" to the services provided by public lands. This condition means that households have no value for the planned investments in those public lands unless they make trips to the sites (Mäler 1974, Smith and Banzhaf 2004). For example, recreationists do not value improvements in trails or stocking streams with fish unless they come to hike or fish. We show that, under this condition, there is a sufficient statistic determining whether an increased gate fee, with revenue reinvested in the site, improves a household's welfare: Namely, an increase in the number of their trips to the site. 
Next, in Section 4, we extend this logic to the gear tax. Like the gate fee, the gear tax can be thought of as taxing a private good that is a weak complement to public lands: Households do not value trail maintenance without boots, or value fish stocks without a rod. Unlike the gate fee, however, the gear tax now involves sellers and a supply price that in principle will respond endogenously to the tax. Nevertheless, we show that, with weak complementarity and oligopolistic competition, our test still holds: If the quantity demanded for the gear increases on net from the joint effect of the tax and the investments it funds, then there is a potential Pareto improvement. More surprisingly, households and firms are better off. That households are better off may not seem surprising, as this result is similar to the gear tax, and the increased elasticity of the supply side can only help the demand side.

That firms are better off may be more surprising. As we discuss in more detail, the basic intuition for this result comes from the way private and public goods are "bundled" so that the tax leverages the benefit principle. In general, private markets work because entrepreneurs find a way to provide valuable services at a price that leaves both sides of the transaction better off. As Anderson and Leal (2001), Anderson and Parker (2013), and Heal (2000, 2003) discuss, entrepreneurs can still perform this function for a public good when it is bundled to a private good. The bundling overcomes the excludability problem. For example, if households do not value wildlife unless they come to visit it, entrepreneurs can invest in wildlife and recoup their investment through the increased demand for a hotel or a tour, which are excludable private goods. As Heal (2003) emphasizes, this logic is most compelling when the entrepreneur is a monopolist, as then there is no free rider problem in the provision of the services. However, in principle, this problem could be overcome by working cooperatively (Ostrom 1991). The gear tax simply plays this coordinating role: If the monopolist would voluntarily make the investment, a group of firms can be "forced" to do so through the tax, and still be better off.

Two points about our analysis should be noted. First, weak complementarity can apply to several private goods (Bockstael and Kling 1988). So our argument would be reinforced when more than one private good is involved. It is certainly possible that demands for tents, backpacks, fishing lures, and so forth would increase with greater investments are made in the public resources supporting the recreational activities that use these private goods. (Whether one would be able to measure the effect of the increase on each of these demands is a separate question.) Second, weak complementarity does not require that the public resource be the only reason for demanding these 
private goods. Thus, people can demand these goods independent of the quality of the public resources. We are only assuming that some individuals will have an increased value for the private goods when the quality of the public resource is enhanced.

Nevertheless, Section 5 relaxes some of the modeling assumptions used in our simplest analysis. In particular, we relax the weak complementarity assumptions and show that our simple test is still a sufficient (but not necessary) condition for both sides of the market to be better off. We also extend the model to account for distributional effects.

Section 6 assembles a variety of empirical information needed to use our first order approximation to develop back-of-the-envelope calculations offering a range of values for the link between a quality improvement and the welfare neutral price increase. Finally, the last section draws together research needs and the implications of what we know for addressing the questions associated with funding park needs in the future.

\section{Bundling and Weak Complementarity}

Economists often make a sharp distinction between private goods, which can be provided by markets, and public goods, usually provided by governments. In many cases, however, households use a "bundle" of public goods and private goods together, to enjoy the services they jointly provide. Outdoor recreation is an example of such bundling. To enjoy a recreation trip, a household bundles together the publicly provided resource (the scenic vistas and built amenities) and their time along with some private goods and services, such as transportation and gear.

This bundling can be modeled as complementarity between the public and private goods. Of course, two private goods exhibit complementarity when a lower price for one leads to greater demand for the other. For bundles of public and private goods, complementarity can be understood as arising when an increase in the availability of a public good leads to an increase in the demand for the private good and, symmetrically, when a lower price for the private good leads to a higher marginal willingness to pay (WTP) for the public good (Madden 1991).

A particularly important type of complementarity relationship between public and private goods is known as weak complementarity (Mäler [1974], Smith and Banzhaf [2004]). Weak com-

plementarity is defined as a situation in which the public good has no value to people unless they also consume positive levels of the linked private good (the weak complement). For example, 
weak complementarity would hold if people don't care about the ecosystem services at a park unless they take trips to it. In other settings, people might not care about local school quality in a neighborhood unless they have housing in the neighborhood; they might not care about local roads unless they drive on them; etc. But the reverse need not hold. The private good's value does not have to be exclusively associated with the services of the public good. People can value local housing without valuing schools.

When exploiting this connection, economic measures of changes in the public good can capture use values. Thus, a decision to rely on the assumption of weak complementarity to measure the benefits from an increase in the amount of a public good rules out non-use values, i.e., values households have for the investment even if they never use it in any instrumental sense. Consequently, the assumption also limits "the extent of the market" to the set of users, even though the set of people who would value the investment may be also larger. This assumption may be problematic for some policy questions, such as the preservation of unique resources such as Yellowstone or the Grand Canyon, or investments that protect ecosystems, where non-use values are important. However, for present purposes, our focus is on funding for deferred maintenance and ongoing operations, not preservation. Though some of these investments may protect ecosystems, many involve more pedestrian objectives like maintaining bathrooms, trails, and campsites which are linked to recreation use. In any case, even if there are existence or nonuse values, we can say that weak complementarity holds for that portion of households' total value linked to recreation.

Weak complementarity is useful because it assures that, when there is an investment in a publicly provided asset, the change in households' Hicksian consumer surplus for their consumption of the private good (that is a weak complement) will be equal to its Hicksian WTP for that investment (Mäler [1974]). Figure 1 depicts the change in consumer surplus for the private weak complement due to this type of investment. It shows the marginal cost of the private good $x$ (e.g. the travel cost of trips to the park) and two Hicksian demand curves for an individual. The lower demand curve shows the quantity of the private good (trips) that would be demanded when income is adjusted to leave the consumer at the same level of utility, when evaluated at a baseline level of environmental or resource quality, $q^{0}$. The upper demand curve shows the corresponding demand at a higher level of environmental quality, $q^{1}$. With people more likely to participate in recreation when the quality of the recreation experience is better, the improvement in environmental quality, shifts up the demand for trips. We assume this shift occurs only through the complementarity 
relationship. Chan and Kotchen (this issue) also account for the additional desirability of taking trips when they become linked, by a dedicated tax, to increases in $q$, making them avenues to voluntary contributions to a public good. ${ }^{6}$

Weak complementarity guarantees that the shaded area between these two lines, up to the level consumed, is the individual's value (or at least the recreational value) of the improvement in $q$. Consider now Figure 2, which depicts the marginal cost of providing the public good $q$ against the marginal social value of a little more $q$. The shaded area in Figure 2 is the (gross) value of the improvement in the public good from $q^{0}$ to $q^{1}$. Weak complementarity guarantees that the two shaded areas in the two figures are the same, for each individual with these preferences. Consequently, the respective sums across individuals of the two areas are the same, and the aggregate value of the investment is equivalent to the change in aggregate consumer surplus for the private weak complement.

A further consequence of this equivalence is that the value of the environmental services (Figure 2) can actually be captured in the market for the private good (Figure 1), when excludability is possible. For example, to the extent households only have recreation values for the services provided by environmental resources, they can be excluded from enjoying them because they can be excluded from entering those areas. This bundling creates incentives for private parties to provide environmental services (Anderson and Leal [2001], Anderson and Parker [2013], Heal [2000, 2003]). As we discuss below in Section 4, it similarly creates the possibility that sellers of gear can benefit from a gear tax. When the bundling relationship is not as salient, as when households have non-use values for the quality improvements associated with investments in a park, households cannot entirely be excluded from enjoying them, making it more difficult for private parties to capture the full value. Nevertheless, as we discuss in Section 5, the presence of partial values may be sufficient to make the case for taxes on some private goods to support improvements in public resources.

In practice, environmental values can be captured in private markets because weak complementarity implies it is possible to define the increase in the price of the linked private good that exactly compensates for the improvement in the public good, leaving the consumer indifferent to the combined change (Willig [1978], Smith and Banzhaf [2004)]). Any actual price increases less than this level would then leave consumers better off. Thus, instead of measuring value through 
income adjustments associated with WTP as economists usually do, one can measure value through price adjustments. However, the "right" price adjustment will differ for each consumer. ${ }^{7}$ Figure 3 reproduces the "fanned" indifference curves from Smith and Banzhaf (2004), which display the way weak complementarity affects the tradeoff between a private good ( $x$ in the diagram) and a numeraire good $(Z)$. The non-market good is $q$. Three indifference curves are displayed. $\bar{U}\left(q^{0}\right)$ depicts the baseline situation, with the consumer's optimum at point B. The dashed indifference curve $\widetilde{U}\left(q^{1}\right)$ indicates that at a higher level of $q$ (with $q^{0}<q^{1}$ ), the consumer obtains higher utility and also purchases more of the private weak complement at point E. The indifference curve $\bar{U}\left(q^{1}\right)$ depicts the combinations of $x$ and $Z$ that leave utility unchanged at the initial level when quality increases. Weak complementarity implies that $q$ has no value to the individual without $x$, thus the two solid indifference curves intersect at the vertical axis because at that point where $x=0$.

The figure illustrates that an increase in the price of the weak complement can be defined that would just compensate for the quality improvement and bring the consumer from $\widetilde{U}\left(q^{1}\right)$ to $\bar{U}\left(q^{1}\right)$, with equilibrium at point C. This price increase represents the source for the potential revenue gain to suppliers of the private good from the investment. In addition to giving them an incentive to provide the investment themselves, it creates the possibility that they can benefit from it even if their own sales are taxed to provide the quality improvement that underlies the increase, a point we return to in Section $4 .^{8}$

\section{The Economics of Gate Fees}

In this section, we show that when trips to public lands are a weak complement to the services provided by the investment in these lands, then it is possible to define a fee increase that, when combined with the investment, leaves households indifferent. If the actual fee required to fund the investment is lower than this critical level, households are better off. To a first-order approximation, this criterion is equivalent to observing an increase in the number of trips from the joint effect of the increased fee and the quality improvement associated with the increased investment.

We model gate fees as comparable to a tax on trips. Trips are a convenient activity to analyze in this way, because conventional practice in modeling recreation demand assumes their price is set by distance between a household's home and the site and by per-mile time and transportation costs, both of which are plausibly exogenous to the policy. Thus, trips to the site (which 
we denote by $x$ ) can be modelled as having perfectly elastic supply at a pre-tax price of $p_{x}$. The price of a composite of other consumption goods is normalized to 1 . Let $q$ be the quality of the site that is visited. Income is fixed and designated by $m$. Let $V()$ represent the indirect utility function for a representative household. Finally, assume that trips are non-rival, so that, if lump sum taxes were available, the optimal gate fee would be zero. ${ }^{9}$

Equation (1) provides the indirect utility function expressed in general terms:

$$
V\left(p_{x}, q, m\right)=\bar{U}
$$

Here, $\bar{U}$ designates the fact that our analysis begins with a baseline level of utility.

Now consider a policy that jointly imposes an arbitrary entry fee $t$ and provides a change in quality $\Delta q$. To start our discussion, we assume that the costs of the improvement $(\Delta q)$ may not necessarily be "covered" by the revenue generated from $t$. To a first order approximation, the change in utility is:

$$
\Delta V \approx V_{p_{x}} t+V_{q} \Delta q
$$

Dividing both sides by the marginal utility of income, $V_{m}$, substituting using Roy's identify for $-V_{p_{x}} / V_{m}=x$, and defining the marginal WTP for $q$ by $\pi=V_{q} / V_{m}$, we have:

$$
\Delta V>0 \leftrightarrow t x<\pi \Delta q
$$

This expression simply says that utility for this person increases if and only if the fee paid, $t x$, is less than the value of the investment, $\pi \Delta q$. This obviously must hold, to a first order approximation.

The assumption of weak complementarity brings additional insight. For any arbitrary $\Delta q$, weak complementarity guarantees that there exists a $t^{*}$ for an individual such that $\Delta V=0$, i.e. $V\left(p_{x}+t^{*}, q^{1}, m\right)=V\left(p_{x}, q^{0}, m\right)=\bar{U}$ (Willig [1978], Smith and Banzhaf [2004]). Returning to Equation (2), this is given by:

$$
t^{*} \approx-\frac{V_{q}}{V_{p_{x}}} \Delta q
$$


More generally,

$$
\Delta V>0 \leftrightarrow t<-\frac{V_{q}}{V_{p_{x}}} \Delta q \approx t^{*}
$$

That is, welfare at the individual level improves if and only if, for any $\Delta q$, the actual fee $(t)$ is less than the critical value $t^{*}$.

Expression (5) can be interpreted more intuitively if we again divide the numerator and denominator of the right-hand term by the marginal utility of income, which, making use of Roy's identity, yields:

$$
\Delta V>0 \leftrightarrow t<\frac{\pi}{x} \Delta q
$$

As $\frac{\pi}{x}$, or the marginal WTP for quality per trip, is a commonly estimated parameter in travel-cost modeling, this condition is, in principle, empirically verifiable. The condition gives us a starting point for determining a neutral tax from the perspective of the representative individual. Thus, if $\Delta q$ is accompanied by a gate fee less than $t^{*}$, then the welfare of the representative visitor is increased by the policy.

However, there is another aspect of this relationship. So far, we have considered simultaneous but essentially arbitrary increases in the fee $(t)$ and in the public good, $\Delta q$. In practice, the ability to realize the $\Delta q$ depends on the aggregate revenue raised from the fee increase or $t N x$, where $x$ is the average number of trips per user and $N$ is the number of users. Budget-balanced combinations of $t$ and $\Delta q$ are limited by feasible production plans. Suppose the cost of providing $\Delta q$ is $C(\Delta q)$. Then for any $\Delta q$, budget balance requires $t=C(\Delta q) / N x .^{10}$

Substituting this relationship into Expression (6), the policy increases aggregate welfare if and only if:

$$
\frac{C(\Delta q)}{N x}<\frac{\pi}{x} \Delta q
$$

or, 


$$
\frac{C(\Delta q)}{\Delta q}<N \pi
$$

That is, the average cost of providing a unit increase in $q$ must be less than the aggregate marginal value of that increase. If one knew $\pi$ but not $C(\Delta q)$, one could back out the break-even cost using this formula. In the simplest case, per-unit costs of increasing $q$ are a constant $p_{q}$ and the test becomes $p_{q}<N \pi$.

This test seems a straightforward application of the Samuelson rule, comparing the supply price of the public good to the sum of the marginal WTP across the $N$ households assumed to experience it. This result may be surprising, as we are not using a lump-sum tax. At first, it may appear that in taking our first-order approximation we have simply assumed away deadweight loss in the market for trips. In fact, the result stems from the fact that weak complementarity guarantees that prices and marginal WTP can be compared in the same space. Our approximation merely simplifies things by translating WTP for quality (Figure 2) into a constant WTP per trip, which shows up as a parallel shift in the demand curve for $x$ (Figure 1). With this simplification, condition (8) guarantees that there is no (net) deadweight loss in the private good to worry about, even though we are not using a lump-sum tax.

In Figure 1, an increase in $q$, taken in isolation, increases the inverse demand curve as shown. As seen in Expression (6), our first-order approximation makes use of a constant $\pi \Delta q / x$, or the WTP for $\Delta q$ per trip. Assuming the WTP per trip is constant implies the inverse demand curve for trips shifts up, in parallel, by $\pi \Delta q / x$. By weak complementarity, the resulting increase in consumer surplus (the shaded area) is equal to the value of an increase in $q$. Just as we can depict the value of $\Delta q$ in the demand for trips, so we can depict the Hicksian-equivalent price adjustment or gate fee. The fee would shift the cost of trips up by $t$. Alternatively, it can be viewed as shifting the demand for trips down, in parallel, by $t$. Thus, we are comparing two vertical shifts in the demand for trips: The shift up from the change in quality, and the shift down from the tax. If the tax equaled the vertical shift up in the demand curve from the increase in $q$, then the demand curve would shift back to its original position, and so the number of trips would be unchanged and consumer surplus would be unchanged. This is precisely what would happen if the fee were set at $t^{*}$. In the figure, the shaded area would equal the gross benefit from the increase in $q$ and the lost consumer from the tax, and the two would offset. Tax revenue would equal $t^{*}$ (the vertical distance 
between the two curves) times the baseline quantity. In general, if the actual fee required to support $\Delta q$ were less, the welfare of users would be higher on net; if it were higher, the welfare of users would be lower on net.

Note we are asking whether a given policy proposal introducing a "bundled" change, namely the fee $t$ that allows a quality improvement of $\Delta q$, is welfare improving. We are not suggesting it is optimal. If lump sum taxes were available, the policy would indeed involve deadweight loss relative to that first-best alternative, as the number of trips would be even higher in that case. Chan and Kotchen (this issue) evaluate alternative taxation schemes from that perspective.

The above analysis suggests, then, that the key question is whether, on net, the demand curve shifts up or down from the joint effect of the excise tax on trips and the quality improvement. As a shift up in a demand curve, with fixed supply, is associated with an increase in the equilibrium quantity of trips, we have the following proposition:

Proposition 1. Under weak complementarity, to a first-order approximation, welfare increases from a combination of a dedicated gate fee and the associated increase in public good services if and only if the quantity demanded implied by the Hicksian demand for trips increases on net.

Such a test could be implemented with standard travel cost models, which predict the effect of costs on trips, if they also can account for the quality change at stake. Our use of the term "associated" is intended to highlight the fact that the aggregate revenue raised from the gate fee must cover the cost of the increase in services.

Under an additional restriction, known as the Willig (1978) condition, this insight leads to an extremely simple ex-post empirical test for a welfare improvement for users. The Willig condition guarantees that the Marshallian variant of the change in consumer surplus for the private weak complement, depicted in Figure 1, also is equivalent to the Hicksian consumer surplus in Figure 2. It is equivalent to restricting the price adjustments discussed above to be invariant to income:

$$
\frac{\partial(\pi / x)}{\partial m}=0
$$

(See Bockstael and McConnell [1993] and Smith and Banzhaf [2004, 2007] for additional 
discussion.) Under this restriction, we can use a net change in the Marshallian consumer surplus for the private weak complement as the basis for our assessment—and, hence, observed changes in the Marshallian demand.

Proposition 2. Under weak complementarity and the Willig condition, to a first-order approximation, welfare increases for users from a combination of a dedicated gate fee and the associated increases in public good services if and only if the Marshallian quantity demanded for trips increases on net.

Thus, ex post, there is no need for estimates of demand, consumer surplus, or costs. If we observe a ceteris paribus increase in trips, we have an increase in welfare.

\section{The Gear Tax}

The previous argument leads naturally to a strategy for analyzing the gear tax. The difference between the gate fee and the gear tax lies in the fact that (i) we must account for the welfare of sellers as well as consumers; (ii) we can no longer assume a perfectly elastic supply as we could in the case of exogenous travel costs, so we must account for market price adjustments; and (iii) the assumption of weak complementarity may not be as plausible for some gear in the tax base as for trips. In this section, we first account for points (i) and (ii), maintaining the assumption of weak complementarity. In Section 5, we relax that assumption as well.

In principle, a gear tax can increase welfare for both consumers and sellers, if it results in a large enough quality improvement in the parks. Figure 4 illustrates the basic argument. It is similar to Figure 1, but we now have added a supply side that responds to price, instead of fixing travel costs at an exogenous level. Let $D^{0}$ represent baseline market demand, as before. Let $D^{\tau}$ represent the demand curve after it is shifted down by the amount of the excise tax on gear, taken in isolation. Let $D^{1}$ represent the ex post demand curve after the revenue is used to improve the quality of one or more parks; it shows the net increase in demand from the tax and the quality effects. Here, we show a case where there is a potential Pareto improvement, with demand shifting up on net. As shown in this diagram, both consumer surplus and producer surplus increase. After the tax and the increase in park quality, as a result of using tax revenue for this purpose, the equilibrium price increases from $P_{0}$ to $P_{1}$. Consumer surplus increases by $A C E B-P_{1} E F P_{0}$, which is positive by construction, and producer surplus increases by $P_{1} C F P_{0}$. Thus, the gear tax can be a strict Pareto improvement, not simply a potential Pareto improvement. 
Figure 4 captures the basic intuition of our argument, but essentially assumes perfect competition. Arguably, perfect competition is an unrealistic assumption, as there are many large purveyors of gear with market power. Market power, in turn, raises the question of whether equilibrium prices would adjust in a way to lower welfare for one group. In fact, in this sub-section, we demonstrate that the basic logic continues to hold under Cournot competition.

Consider the case of $J$ symmetric firms, each with a quadratic cost function for producing a quantity of gear $x_{j}$ :

$$
c\left(x_{j}\right)=\theta+\gamma x_{j}+\frac{1}{2} \delta x_{j}^{2} .
$$

The firms face a linear inverse market demand curve:

$$
p_{x}=a-b X
$$

where $X$ is the total quantity of gear produced, $X=\sum_{k} x_{k}=x_{j}+\sum_{k \neq j} x_{k}$.

Profits for firm $j$ are:

$$
\left[a-b\left(x_{j}+\sum_{k \neq j} x_{k}\right)\right] x_{j}-\theta-\gamma x_{j}-\frac{1}{2} \delta x_{j}^{2} .
$$

Maximizing these profits with respect to $x_{j}$, and taking the production of other firms $x_{k}$ as given, the first-order condition for the firm is to set marginal revenue equal to marginal cost, or:

$$
a-2 b x_{j}-b \sum_{k \neq j} x_{k}=\gamma+\delta x_{j}
$$

Assuming a symmetric equilibrium, then we have $x_{k}=x_{j}$, or, for each firm $j$ :

$$
\begin{gathered}
a-b(J+1) x_{j}=\gamma+\delta x_{j} \\
x_{j}^{*}=\frac{a-\gamma}{\delta+b(J+1)} .
\end{gathered}
$$

The total quantity is $J$ times this value, or 


$$
X^{*}=\frac{(a-\gamma) J}{\delta+b(J+1)} \text {. }
$$

Finally, the equilibrium price is given by substituting this equilibrium quantity back into the inverse demand function, $p_{x}^{*}=a-b X^{*}$ :

$$
p_{x}^{*}=a-b \frac{(a-\gamma) J}{\delta+b(J+1)} .
$$

Consider next the question, how does the gear tax affect this equilibrium? As always, we can model an excise tax, in isolation, by shifting the demand curve down by an amount $t$, effectively replacing $a$ with $a-t$ in the demand curve and in the equilibrium price and quantity. As the revenue is used to enhance quality of one or more parks, following our analysis in Section 3, we can view this effect, to a first-order approximation, as a parallel shift up in the demand curve for gear. Denote the net effect of these two parallel shifts as $d a$ (i.e., the change in the intercept of the demand curve).

At the margin, the net effect of this tax/quality enhancement on the equilibrium quantity is $d X^{*}=\frac{\partial X^{*}}{\partial a} d a$, or:

$$
d X^{*}=\frac{J}{\delta+b(J+1)} d a .
$$

This term will have the same sign as $d a$. Thus, if the net effect is to shift demand up, the equilibrium quantity demanded and quantity supplied increases in the Cournot model. By the same token, the change in price is $d p_{x}^{*}=\frac{\partial p_{x}^{*}}{\partial a} d a$, or

$$
d p_{x}^{*}=\left[1-\frac{b J}{\delta+b(J+1)}\right] d a .
$$

And this price change also is the same sign as $d a .^{11}$

Thus, firms are clearly better off: A shift up in the demand curve leads to higher sales and higher prices, which increases profits. Thus, even though they bear some of the burden of the tax, firms benefit on net if the feedback effect of the quality improvement on demand is sufficiently 
large.

What about consumers? Consider the Marshallian consumer surplus in this market, $\mathrm{CS}=$ $\frac{1}{2} X^{*}\left(a-p_{x}^{*}\right)$. Substituting in the above expressions for $X^{*}$ and $p_{x}^{*}$, we have:

$$
C S=\frac{1}{2}\left[\frac{(a-\gamma) J}{\delta+b(J+1)}\right]\left[b \frac{(a-\gamma) J}{\delta+b(J+1)}\right]=\frac{b}{2}(a-\gamma)^{2}\left(\frac{J}{\delta+b(J+1)}\right)^{2}
$$

If we consider how the consumer surplus changes with $a$ (i.e. $d C S=\frac{\partial C S}{\partial a} d a$ ), we have:

$$
d C S=b(a-\gamma)\left(\frac{J}{\delta+b(J+1)}\right)^{2} d a
$$

Again, this change in consumer surplus is the same sign as $d a$ (assuming an interior solution where the demand curve intersects the supply curve, which occurs where $a>\gamma$ ). Thus, consumer surplus also increases if the demand curve increases.

Moreover, as perfect competition and a single-price monopoly are special cases of Cournot with $J=\infty$ and $J=1$, respectively, the result holds in those limiting cases as well.

Of course, we usually measure consumer welfare with Hicksian surplus, not Marshallian consumer surplus. Since we are using a first-order approximation in terms of price, we are effectively assuming the price/ quality relationship is not affected by income (and thus we are implicitly using the Willig condition, along with weak complementarity in this argument). Thus, we have the following proposition:

Proposition 3. Under weak complementarity and the Willig condition, and under Cournot competition, perfect competition, or monopoly pricing, welfare increases for both consumers and sellers from a combination of a dedicated gear tax and the implied corresponding increase in public good services if and only if the Marshallian quantity demanded for gear increases on net.

In sum, the test is the same as that from Section 2: To a first-order approximation, our gauge of the effects was given earlier by Expression (7) or (8), repeated here:

$$
t<\frac{\pi}{x} \frac{N x t}{p_{q}}
$$




$$
p_{q}<N \pi
$$

The demand curve shifts down by $t$ and shifts up by the value of $q$ per unit of gear $\pi / x$ times the change in $q$ that is consistent with the increased revenues or, given our simplifying assumptions, $N x t / p_{q}$. So, to a first-order approximation, we still have a gauge of whether $p_{q}<\pi N$, for gear as well as for trips. ${ }^{12}$

\section{Reflections on Bundling}

The argument that a public good funded with a dedicated tax can make households better off is not new. The conclusion that it can make firms better off as well may be more surprising. The potential for this result stems from the bundling made possible by weak complementarity, which increases the demand for the taxed good. It relies on the strength of the link between the public good and its weak complement as well as being able to increase the public good services sufficiently, given the extent of the market for that private good. Potentially, this linkage creates incentives for entrepreneurs to contribute to the public good by bundling it to private goods (Anderson [1998], Anderson and Leal [2001], Anderson and Parker [2013], Banzhaf, Fitzgerald, and Schnier [2013], Chichilnisky and Heal [1998], Heal [2000, 2003]). One prominent example is ecotourism. When tourists visit a preserve in southern Africa to view elephants and other wildlife, they cannot obtain the use values for these services unless they also consume a linked private good, such as the guided safari. Furthermore, because they do not enjoy the ecosystem services unless they also purchase the private goods associated with the trip, they can effectively be excluded from enjoying the use related services of the ecosystem as well. Similarly, when the wildlife is better, the demand for the safaris is higher. Consequently, the safari guide has an incentive to conserve and maintain elephant habitat. The South African company andBeyond (formerly Cons-Corp) does precisely this; buying up land from ranchers that is far more valuable as elephant habitat (Anderson [1998], Heal [2000]).

In his analysis of such incentives, Heal (2003) identifies three necessary conditions. The first is weak complementarity. There are no non-use values, so the African ecosystem services are exclusively associated with use-related activities. The second is that the private good be sold by a monopolist. This condition is important because it evades the "free rider" problem in the provision of the public good. For example, when the outfitter invests in improving the ecosystem services 
of the park, as a lone seller it would capture the full benefit of the increased demand for trips to the park, so it has the full incentive to make the investment. With many sellers, this is no longer true. Each of them would benefit from an improvement in ecosystem services but would prefer to let the others bear the expense of the improvement.

Heal's third condition is not only that the private good be sold by a monopolist, but that it be sold by a perfectly price discriminating monopolist. Thus, for goods that sell in varying quantities, the seller can offer an "all-or-nothing deal" for a specific quantity that leaves the customer just indifferent to buying the bundle or not. This third condition completes a syllogism at the heart of Heal's logic:

- By weak complementarity, the Hicksian value for an investment in the public good is equal to the change in the Hicksian value for the linked private good.

- Because it is a perfectly discriminating monopolist, the seller can capture the full Hicksian value of the private good.

- Therefore, the seller captures the full Hicksian value of the investment in the public good. Thus, in Figure 1, the seller's marginal increase in profits from an improvement in the public good is the same as the shaded area marked as the social benefit. This area is equivalent to the area marked in Figure 2. Comparing this area to the cost of the investment, the seller provides the public good up to the optimal level, $q^{*}$.

Our analysis of the gear tax is similar, insofar as the value is potentially created through investments in natural resources and captured by private sellers of a linked weak complement. It differs in that, because the seller is not a monopolist, there is the potential for free riding. But taxes are a standard way to overcome such free-rider problems. In this case, if sellers of gear would benefit jointly from increased investment in public lands, the gear tax would represent a coordinating mechanism that assures they participate. An analogy might be made to commodity checkoff programs, where dairy farmers pay collectively for an ad campaign ("got milk?") that benefits them collectively.

This possibility parallels other, more familiar, situations where demand for a private good is higher because it is taxed, with the revenue ploughed back into a complementary public good. Vehicles and roads are weak complements: One doesn't value the maintenance of roads unless one drives a vehicle. Total driving is probably greater because of the gas tax and the road 
improvements it funds (relative to a counter-factual without that transportation funding). Likewise, housing in a community and its public schools and other local, government provided services, such as police or fire protection, are weak complements. Housing demand is surely higher in an area with a property tax than it would be if there were no tax and no public services. Finally, and closest in theme, the Pittman-Robertson program which taxes hunting and fishing equipment to support public lands is popular both with industry as well as with hunters and anglers. They want to be taxed, so long as the revenue is reinvested into maintaining the resources they use. In the same way, sellers of gear might benefit from being taxed if the money were reinvested in the parks and if the complementarity between gear and the services provided by the investment is strong enough.

\section{Extensions}

In this section, we consider four extensions to our analysis: Relaxing our assumption of weak complementarity between the private and public goods, considering multiple goods, analyzing distributional effects, and allowing for both pure and "warm glow" giving to the public good.

\section{Relaxing Weak Complementarity}

Till now, we have maintained that the private good being taxed (trips or gear) is a weak complement to the public good and that the resulting increased revenue is used to increase the amount or quality of that public good. As noted previously, this assumption rules out non-use values. When this assumption is appropriate depends on how the revenues are used. If the revenues are used for services that specifically support recreation (access roads, trail maintenance, camp sites, etc.), then ignoring nonuse values is reasonable. If the revenue is used to support habitat or protect water quality, especially at unique sites like Yellowstone or the Grand Canyon, however, non-use values may need to be considered in evaluating the tax. These non-use values may increase the total value of users or may increase "the extent of the market" by extending it to nonusers.

A related issue is that our first-order approximation basically assumed demand curves for the private weak complement shift up vertically, as a constant value per trip or unit of gear, so that quality improvements in the public good show up in increased sales of the private goods at the margin. However, in principle, weak complementarity only requires that they shift up over some portion of the domain of the demand for the private good. It is possible that they could shift up 
infra-marginally, but not at the margin. Greater public good services may increase the number of times a recreationist uses the boots or the fly rod and/or increase the value of each use, but not increase the number of pairs of boots or fishing rods purchased. If so, an investment in public lands would increase the consumer surplus for gear, but not necessarily the quantity demanded. Without non-linear pricing, as invoked by Heal (2003), capturing such values will be challenging.

If either nonuse values or these inframarginal effects are important, then some social value is not captured by sellers in the linked private market. In that case, our result is a sufficient but not necessary condition: If the demand for the weak complement increases, then there is a Pareto improvement. But the converse is not true: Even if demand for the weak complement decreases, we cannot rule out the Pareto improvement. Thus, our approach essentially identifies a lower bound on values.

\section{Multiple Weak Complements}

In the case of outdoor recreation, several types of gear as well as transportation all might serve together as a bundle of weak complements to environmental amenities. Thus, a free-flowing river with enhanced water quality could support salmon fishing, kayaking, hiking (along the river), and bird watching (where unique species might be attracted to the area by the fish, etc.), all over the course of a year, with each activity associated with its own respective gear. In this case, the value of the improvement in the public good is equal to the sum of the sequential changes in consumer surplus for all the weak complements, including trips and gear (Bockstael and Kling 1988). In terms of Proposition 3, the first-order approximation becomes a test about an index numberessentially whether gear-related expenditures increase when measured at constant prices.

A related issue is whether, even for recreation-based values, weak complementarity is applicable to the case of gear. We believe it is. Weak complementarity only implies that households have, e.g., no value for trail maintenance if they don't use their hiking boots for hikes. It does not require that, symmetrically, they don't value the boots without the trail work. More generally, different gear is associated with different activities and might not be exclusively associated with the improved recreation sites or activities. The issue then becomes whether the effects of the enhanced value in the taxed markets are large enough that the increased revenues could be captured by sellers or the increases due to the enhancements detected by analysts. That is, whether the link between the private goods and the public good is strong enough to assure the feedback effects on 
the entire tax base offset the price increases. In this case, our test remains valid, but we might not expect to pass it.

\section{Distributional Effects}

So far, for simplicity, our analysis has basically assumed a homogenous group of households and firms. When there is heterogeneity, our aggregate test becomes a test of a potential Pareto improvement, rather than an actual Pareto improvement (with consumer surplus increases on net but not necessarily for every individual). However, the test can be extended to account for distributional effects. In the case of entry fees, for example, Proposition 2 could be implemented on a group-by-group level. Groups might be defined by demographic categories, as in the papers by Ji et al. and Lupi, von Haefen, and Cheng in this issue, or by residential location, as in the paper by von Haefen and Lupi in this issue. If, for a particular group, we observe a ceteris paribus increase in trips, then that group's welfare has increased. If another group's travel decreases on net, their welfare has decreased. In this way, our test potentially can be used to identify net transfers from one group to another, provided we can observe the separate responses of these groups. This issue of heterogeneity and distributional effects also interacts with the issue of nonuse values. If households in a particular group have high nonuse values, they may benefit even though they do not contribute to the cost through fees, but the benefits they realize would not be detected by our test.

Similarly, for the gear tax, one might segment households and apply Proposition 3 across groups. To test for heterogeneous effects across firms on the supply side, one could simply implement Proposition 3 on an industry-by-industry basis. If demand shifts up on net in a given industry, firms in that industry are better off. There are good reasons to believe there will be heterogeneous effects, especially with respect to the gear tax. The tax may apply to private goods consumed by nonusers of the resources that are improved by the tax, as well as users. These other consumers would incur the price increase but not realize the gains associated with the investments in ecosystem services. Even if our test shows users benefit on net, for non-users we would not expect to find an increase in their demand for gear, and we would find they are made worse off. Of course, implementing these tests requires appropriately segmented data.

\section{Voluntary Contributions to Public Lands}

One last extension bears on the ability of firms to capture some of this increase in economic 
value, even non-use value. This possibility arises from people's desire to make voluntary contributions to public lands. Even some non-use value may be captured by sellers of a private good if consumers are willing to donate to public lands and view the higher prices as an indirect mechanism for such donations. For example, organizations like REI and Patagonia donate revenue to causes associated with preserving environmental amenities. 4Ocean uses materials collected in cleaning marine debris in its products. These firms use these connections to promote their products. With the gear tax, one could imagine stickers on taxed goods proclaiming " $t$ percent of every dollar goes to funding public lands." Kotchen $(2005,2006,2013)$ refers to such situations as "mixed public goods", which bundle an excludable private good (like gear) with a contribution to a public good. If individuals are partly motivated by either voluntary contributions to the public good, even indirectly by buying a good where some of the revenues are donated, as considered by Chan and Kotchen (this issue), or the good feelings of making the donation ("warm glow"), then they can be excluded from that part of the package. They cannot receive the satisfaction of making a donation unless they actually donate, which is itself a form of weak complementarity (Banzhaf, Fitzgerald, and Schnier 2013). This argument suggests we now have three effects shifting the demand curve for the private good: The tax would shift it down, the public services shift it up, and the opportunity to donate (and receive warm glow) also shifts it up. This last effect changes the extent of the market to include people who may not be as concerned about how much their personal recreation experience is enhanced but do gain nonetheless by knowing they "did their part" to sustain public lands.

\section{Empirical Evidence}

Despite the extensive economic literature on outdoor recreation, we know surprisingly little about some of the questions posed in this paper. For sixty years, the workhorse model of recreation valuation has been the travel cost model, in which travel costs are meant to be equivalent to the effect of a gate fee. ${ }^{13}$ While well positioned to address some of our questions, to date the travelcost literature has focused on consumer surplus, ignoring the revenue actually collected by the gate fee. It also has tended to focus on questions associated with the valuation of natural amenities, with less emphasis on how the amenities would be maintained or enhanced with any new revenue that resulted from the fees. More recently, Ji et al. (this issue) take this issue on directly. Von Haefen and Lupi (this issue) similarly consider, not how revenue might be reinvested to have feedbacks on the demand for sites, but how the tax itself might do so through its effects on congestion. 
For the gear tax, the empirical challenges are even greater. The central empirical challenge we face is developing estimates for how the improvements in park quality would affect the demand for recreational gear. This effect underlies the shift in demand we described in Figure 4. Critically, data do not include measures for the activities involved with the gear or the locations where the gear was used. Thus, making the connection between park quality and gear is difficult. When park use has been studied in recreation demand studies, the quality features considered are usually not related to the ones that might be affected by the activities associated with how parks are maintained. As a result, we selected two sets of estimates for the value of national parks and adapted them in an approximate way to develop estimates of the value share, which can be used to implement the logic implied by equation (6).

With some substitutions, we can rewrite Expression (6) in percentage terms, making it more useful for use with the available data:

$$
\frac{t}{p_{x}^{0}}<\frac{\pi q^{0} / m}{p_{x}^{0} x / m} \cdot \frac{\Delta q}{q^{0}}
$$

This expression gives us a starting point for determining the magnitude of a neutral tax (i.e. one where the quality increase exactly offsets the negative effect of the increased price(s) due to the taxes on gear). In our setting, we do not know $p_{x}^{0}$, so we do not know whether the enhancement in the public good can be paid for the revenues raised by the increased gate fees or gear tax. However, we can still find the critical value $t^{*}$ that would leave recreators indifferent. A proportionate tax of $t / p_{x}^{0}$ that is less than what is implied by the right side of equation (21) would improve welfare for a representative recreating household.

In other words, by comparing the value share for the services associated with park quality as a fraction of income $\left(\pi q^{0} / m\right)$ to the share of income spent on gear $\left(p_{x}^{0} x / m\right)$, we have a gauge of how much the price can increase (due to the tax) for each percentage point increase in quality. For example, if the value share for park quality is about $1 \%$ of income and expenditures on gear about $2 \%$, then the price increase that would hold WTP constant for a representative individual (with simultaneous improvements in park quality) would be half the percentage increase in quality. Larger value shares for park quality would allow for larger price increases.

In this section, we provide some suggestive evidence on the range of price increases for a 
given improvement in park quality that would be WTP neutral, as we defined this idea in Section 3. Our estimates leverage some diverse sources for estimates of the components of equation (21). They mix data from different household samples and different time periods. As a result, they are best viewed a "collage of estimates" that were collected to match up available information with the task at hand and should be interpreted as illustrative examples of what could be done once there are better data. If the logic associated with our ratio of shares proves useful, then implementing it will require a more extensive effort to assemble consistently defined measure for each of the shares.

The first parameter we require is the income-share of park quality, $\pi q^{0} / m$. To estimate this parameter, we use both revealed preference and stated preference results in the literature. The results for the revealed preference study we selected (Parsons et al [2021]) are in the top panel of the Table 1. The first column provides the names for each of the Southwestern Parks included in this study. The second column provides the estimate reported in the study for the WTP to avoid removing one of the parks from a set that was visited as a group during a vacation trip. Essentially the study assumed each visit was part of a planned trip that included visits to multiple sites. The data were collected with on-site surveys in each of the seven parks considered as part of the study. Initial contacts were made to potential survey respondents in the parks as they entered during a specific time window, and then these individuals were sent follow up surveys to collect the specific data used in the analysis. Our results are taken from one of the models reported in Parsons et. al. (2021), a standard random utility model where the choice set involved different portfolios of parks to be visited. The model assumes the trip is undertaken and the choice set is among a group of alternative portfolios. Each of these alternatives is assumed to involve a distinct mix of Southwestern Parks. This process defined a composite of multiple site choice alternatives. The costs then correspond to the costs associated with altering the mix of sites, given the respondent has already taken the trip.

The measure we selected for WTP considers a situation where the model is calculating the amount that would be paid to avoid removing each site, one at a time, from the portfolio. Our estimate is the average for each site over all possible combinations considered for the portfolios and for all of the respondents in the sample in $2002 \$$. To arrive at the value share for each site as part of an annual vacation, we added the average trip expenditures for the vacation from the sample (\$822) to the incremental WTP as defined in the analysis (given in the second column) for the 
park. We then compare this sum to an estimate of the average respondent's income. The results, representing our estimates of $\pi q^{0} / m$ for each park, are shown in the third column of Table 1 . The numerator is a measure of the contribution of an individual park, as a "quality" indicator for an overall recreation trip that included visiting multiple parks. We recognize this interpretation is a "stretch." For illustrative purposes, we view this as a "calibration" exercise required because the revealed preference literature does not appear to have better measures for how the maintenance of a park contributes to the quality of a recreation trip composed of visiting Southwestern parks. As a result, we pose a thought experiment: If quality declines associated with lack of maintenance would eliminate a park from a recreationist's planned portfolio, how much would that person pay to support the maintenance that allows it to continue to be part of the composite of sites visited?

The second set of information required for our ratio in equation (21) is the share of income for recreational gear, $\left(p_{x}^{0} x / m\right)$. We use two sources to estimate the share. The first is an Outdoor Recreation Association (2017) study. The study uses a pre-existing, large, internet panel to provide a representative sample and asks about expenditures on recreation equipment and participation in thirty-eight activities. Their analysis involved a national survey in 2016 of spending on recreation gear for each of 38 activities. We selected three non-motorized activity groups to construct the share measures-camping, hiking, and mountaineering. Camping includes trips that involve sleeping in a tent or in a lodge; hiking was defined as a day hike; and mountaineering corresponded to a composite of three activities, backpacking, mountaineering, and rock or ice climbing. The report did not include household incomes of the respondents. To convert these values to expenditure shares, we use the 2016 median household income as reported by the St. Louis Federal Reserve Bank. ${ }^{14}$ These annual shares are given for each of the three activities in the second row of the table.

Our estimated expenditure share for wildlife viewing was taken from a different source. ${ }^{15}$ We use the 2016 National Survey of Fishing Hunting and Wildlife Associated Recreation. This survey reports equipment expenditures including both for those involving trips around the home and away from the home. We consider the total of these expenditures, omitting trip related expenses, for our measure of gear related expenses. Median household income for those undertaking wildlife viewing away from home was used to compute these ratios. These estimates are also reported in the second row of the table. 
The remaining cells in the top panel of Table 1 can then be interpreted as an array, with each row corresponding to one value of $\pi q^{0} / m$ and each column corresponding to one estimate for the value of $p_{x}^{0} x / m$. Each cell in the matrix computes the ratio of the two, as used in equation (21). All the estimates exceed unity, implying the tax, in percentage terms, can exceed the quality improvement for parks in percentage terms. The analysis does not consider whether the revenue raised would be sufficient to pay for the increase in quality. We consider these estimated ratios as alternative measures for the scaling factor we defined for computing the WTP neutral price increase for gear. Each provides an alternative estimate, depending on which of the Southwest parks and type of gear measures was considered most plausible, as an example that best fits the logic underlying equation (21). The measures for wildlife viewing are the smallest, but nonetheless imply taxes, in percentage terms, could be 30 to 40 percent larger than the percentage improvement in park quality. If we consider the activity specific gear measures, where the income shares are smaller, the increases can be as large as 4.5 times the percentage improvement in quality.

The second panel in the table repeats the logic with a different source for the measure of the value share for park quality. We use the Haefele et. al. (2020) stated preference analysis of alternative proposals to address the need for added park funding. This study uses a national sample, not one based on on-site sampling as was the case for the above revealed preference estimates. The contingent valuation question presents alternative policies to reduce the size of the park system by selling different amounts of parks, presented in terms of acres or sites sold, as a composite including nature based, historic, and water based parks with these terms and the total amounts defined in the survey. The nature-based and water-based groups are presented as lost acres (from the sales), implying portions of the park acres would be sold off, not necessarily individual parks. For the historic category of parks, the amount sold is presented as sites sold.

Three alternative sets of losses, along with an annual income tax increase to avoid the policy are presented in the first choice question. ${ }^{16}$ Each respondent is asked to indicate their most preferred and their least preferred alternatives. The option of no change in parks is included with the largest required tax increase of the three presented to each respondent. Separate amounts of tax increase were set for the no sales case, ranging from $\$ 115$ to $\$ 600$. For the cases with sales the amounts sold ranged from 20 to $40 \%$. For the maximum case and the amount of the tax increase was always zero. The middle case was a smaller amount of sales, zero to ten percent, and smaller tax increases, $\$ 15$ to $\$ 100$. Fifteen different combinations were considered, varying the 
percentages sold and tax amounts with the restrictions on the tax amount for the largest amount sold and for the no sale cases imposed. A rank logit estimator was used to estimate the WTP measures.

The estimates developed for each policy alternative are based on using the estimated parameters from the model to compute a marginal WTP and rescaling that measure by the amount (in acres or sites) for the alternative considered. This "unit value" was then the basis for the WTP measures reported in the bottom panel in Table 1 for this study. Many questions could be raised about the implicit assumptions in our somewhat ad hoc benefit transfer strategy to develop these estimates. Due to the limited number of available estimates, we simply used their estimates for WTP and median income to provide another source for the measuring the park quality share.

As expected, given the difference in the object of choice used to measure the numerator of our WTP neutral scaling factor, these ratios are dramatically larger than those based on the Parsons et. al (2021) study of specific Southwestern parks. Neither study ideally matches our needs. Taken as a whole, these estimates simply provide an approximate range for what to expect in efforts using current research to estimate the willingness-to-pay-neutral scaling factor. Given that the scale of the deferred maintenance and associated park quality is large, small overall improvements in the quality of the system are the likely result of any new funding source. Nevertheless, these "rough" estimates suggest a larger price increase (in percentage terms) would be consistent with a WTPneutral effect, provided they actually raised sufficient revenue to support the quality enhancements. The implication of this assessment is that, based on the logic outlined in Figure 4, taxes that, as a percent of gear prices, are larger than the park quality increases in percentage terms can still increase welfare for both buyers and sellers.

\section{Concluding Discussion}

Our empirical analysis in Section 6 illustrates how our approach to dedicated taxes could be implemented in practice. However, our experience with it has highlighted how far the otherwise advanced literature on recreation demand currently is from addressing the questions posed here. Four areas stand out as needing additional attention. First, better, more detailed data is needed on the actual projects for which public lands need (or claim to need) funding. We attempted to obtain park-level maintenance information and were told these data did not exist in convenient form and would be difficult to develop. Second, while travel and other costs incurred by the user are well 
studied, more information is needed on the cost of a user-day on public lands. One of the first comprehensive analyses of the economics of outdoor recreation by Clawson and Knetsch (1966) devoted two sections to analysis of the costs, but provided only general descriptions of the economic principles underlying cost analysis without specific attention to the measurement of output and how that impacts the treatment of inputs and costs. The CRS (2019) discussion of deferred maintenance defines maintenance to "...include a variety of activities intended to preserve assets in an acceptable condition, including activities such as preventative maintenance and replacement of parts, systems, and components" (p. 1). ${ }^{17}$ The average cost per user-day and how it differs at the margin would be useful for setting optimal fees.

Third, more consideration should be given to the political economy of fees and taxes. Policy must address the diverse sources of revenue within an agency and the way that revenue is shared across individual units. For example, Congressional appropriations for each of the 419 units of the NPS are line items in its overall appropriation. Under current rules, these allocations cannot be altered by the Secretary of Interior or the Director of the National Park Service. Additional revenue sources may change those appropriations or the way they are allocated across sites. Gate fees at least have the potential to be kept local, keeping the finance mechanism closer aligned with the benefit principle and preserving incentives for managers to run their facilities well. In the case of gear, such subsidies are more likely, as presumably it would be taxed at a national level and then distributed. How revenue would be shared and the incentives those sharing rules create would be crucial for understanding the effects of policy, but our analysis here abstracts from these questions.

Finally, despite over 50 years of travel cost modeling, the literature on the economic value of public lands almost entirely ignores the incremental value of mundane investments in $\mathrm{M} \& \mathrm{O}$ that are the actual everyday concern of managers. It also ignores questions about how increased fees affect revenues. Instead, it focuses almost exclusively on the consumer surplus for the existence of a site, or perhaps improvements in water quality or air quality. Many benefit studies appear to be driven more by efforts to illustrate new methods than to obtain measures of trade-offs for specific policy questions.

Estimates of marginal values for other types of investments, along with their cost, could help managers of public lands with specific decisions. We have shown that, when public goods 
are bundled together to one or more private goods that are weak complements to that public good, there is a very simple test for whether increases in the prices of the private goods or in the gate fees (or both) that are reinvested in the public good will increase welfare: Namely, that the demand for the private good shifts up on net. A similar test implies both consumers and sellers of a private good would benefit from a gear tax.

Our application took a public-finance perspective on the management of public lands. However, the same approach could be applied to a marketing perspective for private lands or monopoly-owned weak complements. Interestingly, weak complementarity has been used in two distinct literatures which, to our knowledge, have not previously been connected. First, it has been used in non-market valuation for purposes of benefit-cost analysis (Mäler 1974). Second, it has been used in the analysis of private incentives to provide public goods (Anderson and Parker 2013, Heal 2003). Our theoretical analysis of the gear tax synthesizes these two perspectives. If there is a way for an analyst to estimate value from market behavior, then there may be a way for entrepreneurs and markets to capture that value. Thus, this restriction plays a role in "bottom-up" (Hayekian) as well as "top-down" (Lange-Lerner) approaches to value. 


\section{References}

Anderson, Terry L. 1998. "Viewing Wildlife through Coase-Colored Glasses." In Who Owns the Environment?, ed. By Peter J. Hill and Roger Meiners. Lanham, MD: Roman \& Littlefield, pp. 259-82.

Anderson, Terry L., and Donald R. Leal. 2001. Free Market Environmentalism, $2^{\text {nd }}$ ed. New York: Palgrave.

Anderson, Terry L., and Dominic P. Parker. 2013. "Transaction Costs and Environmental Markets: The Role of Entrepreneurs." Review of Environmental Economics and Policy 7(2): 259-75.

Banzhaf, H. Spencer, Timothy Fitzgerald, and Kurt Schnier. 2013. "Nonregulatory Approaches to the Environment: Coasean and Pigouvian Perspectives." Review of Environmental Economics and Policy 7(2): 238-58.

Bockstael, Nancy E., and Catherine L. Kling. 1988. "Valuing Environmental Quality: Weak Complementarity with Sets of Goods." American Journal of Agricultural Economics 70(3): 654-62.

Bockstael, Nancy E., and Kenneth E. McConnell. 1993. "Public Goods as Characteristics of NonMarket Commodities." Economic Journal 103: 1244-57.

Bresnahan, Timothy F., and Robert J. Gordon. 1997. "Introduction," in The Economics of New Goods, ed. by Timothy F. Bresnahan and Robert J. Gordon. Chicago: University of Chicago Press for National Bureau of Economic Research, pp. 1-26.

Chan, Nathan W., and Matthew J. Kotchen. 2021. "Funding Public Goods through Dedicated Taxes on Private Goods." Land Economics, this issue.

Chichilnisky, Graciela, and Geoffrey Heal. 1998. "Economic Returns from the Biosphere." $N a-$ ture 391: 629-30.

Congressional Research Service (CRS). 2020a. "Federal Lands Recreation Enhancement Act: Overviews and Issues." updated, August 21.

Congressional Research Service (CRS). 2020b. "National Park Service Deferred Maintenance: Frequently Asked Questions" (author Laura B. Comay), updated,May 13.

Congressional Research Service (CRS). 2021 "National Park Service: FY2021 Appropriations"(author Laura B. Comay) updated January 26.

Congressional Research Service (CRS). 2019a. "Deferred Maintenance of Federal Land Management Agencies: FY2009-FY2018 Estimates and Issues" updated April30. R43997

Congressional Research Service (CRS). 2019b. "Land and Water Conservation Fund: Appropriations for "Other Purposes" updated May 14. R44121 
Congressional Research Service (CRS). 2019c. "National Park Service Appropriations: Ten Year Trends" (author Laura B. Comay) updated July 2. R42757.

Faias, Marta and Emma Moreno-Garcia. 2019. "On the Private Provision and Use of Public Goods." Unpublished paper.

Fretwell, Holly Lippke. 1999. "Paying to Play: The Fee Demonstration Program." PERC Policy Series PS-17.

Haefele, Michelle, John Loomis, and Linda J. Bilmes. 2020. "Total Economic Valuation of the National Park Service Units and National Park Service Cooperative Programs." In Valuing U.S. National Parks and Programs: America's Best Investments, ed. by Linda J. Bilmes and John B. Loomis. New York: Earthscan from Routledge, pp 16-44.

Heal, Geoffrey. 2000. Nature and the Marketplace: Capturing the Value of Ecosystem Services. Washington, DC: Island Press.

Heal, Geoffrey. 2003. "Bundling Biodiversity." Journal of the European Economic Association 1(2-3): 553-60.

Ji, Yongjie, David A. Keiser, Catherine L. Kling, and Daniel J. Phaneuf. 2021. Revenue and Distributional Consequences of Alternative Outdoor Recreation Pricing Mechanisms: Evidence from a Micro Panel Data Set. Land Economics, this issue.

Kotchen, Matthew J. 2005. "Impure Public Goods and the Comparative Statics of Environmentally Friendly Consumption." Journal of Environmental Economics and Management 49: 281-300.

Kotchen, Matthew J. 2006. "Green Markets and Private Provision of Public Goods." Journal of Political Economy 114(4): 816-34.

Kotchen, Matthew J. 2013. "Voluntary- and Information-Based Approaches to Environmental Management: A Public Economics Perspective." Review of Environmental Economics and Policy 7(2): 276-95.

Lindahl, Erik.1958. "Just Taxation -A Positive Solution" (English translation). In Classics in the Theory of Public Finance, edited by R.A. Musgrave and A.T. Peacock. London: Macmillan.

Loomis, John B., and Rodney W. Olson. 1985. "Potential Federal Funding of State Nongame Management Programs: Results of a US Fish and Wildlife Service Study." Transactions of the North American Wildlife and Natural Resources Conference 50: 374-82.

Lupi, Frank, Daniel J. Phaneuf, and Roger von Haefen. 2020. "Best Practices for Implementing Recreation Demand Analysis." Review of Environmental Economics and Policy 14(2): $302-23$.

Lupi, Frank, Roger H. von Haefen, and Li Cheng. 2021. "Distributional Effects of Entry Fees 
and Taxation for Financing Public Beaches." Land Economics, this issue.

Madden, Paul. 1991. "A Generalization of Hicksian $q$ Substitutes and Complements with an Application to Demand Rationing." Econometrica 59(5): 1497-1508.

Mäler, Karl Göran. 1974. Environmental Economics: A Theoretical Inquiry. Baltimore: John Hopkins University Press for Resources for the Future.

Musgrave, Richard A. 1959. The Theory of Public Finance: A Study in Public Economics. New York: McGraw Hill Book Co.

Myles, Gareth D. 1995. Public Economics. New York: Cambridge University Press.

Outdoor Recreation Association. 2017. The Economic Contributions of Outdoor Recreation: Technical Report on Study Scope, Methods, and Procedures. Fernandina Beach, FL: Southwick Associates, August.

Parsons, George, Chris Leggett, Joseph Herriges, Kevin Boyle, Nancy Bockstael, and Zoe Chen. 2021. "A Site-Portfolio Model for Multiple-Destination Recreation Trips: Valuing Trips to National Parks in the Southwestern USA." Journal of the Association of Environmental and Resource Economists 8(1): 1-25.

Phaneuf, Daniel J., and V. Kerry Smith. 2005. "Recreation demand models." In Handbook of Environmental Economics, Vol. 2, ed. by Karl-Göran Mäler and Jeffrey R. Vincent. (Elsevier)Pp. 671-761.

Ramsey, Frank P. 1927. "A Contribution to the Theory of Taxation." Economic Journal 37:47-61.

Smith, V. Kerry, and H. Spencer Banzhaf. 2004. "A Diagrammatic Exposition of Weak Complementarity and the Willig Condition." American Journal of Agricultural Economics 86: 455-66.

Smith, V. Kerry, and H. Spencer Banzhaf. 2007. "Quality Adjusted Price Indexes and the Willig Condition." Economics Letters 94: 43-48

US Department of the Interior (US DOI). 2018a. "Certificate of Apportionment of \$797,160,562 of the appropriation for Pittman-Robertson Wildlife Restoration (CFDA No. 15.611)..." Memorandum FWS/AWSR/AIM:067398. March 20, 2018.

US Department of the Interior (US DOI). 2018b. "Certificate of Apportionment of \$351,917,483 of the appropriation for Dingell-Johnson Sport Fish Restoration (CFDA No. 15.605)..." Memorandum FWS/AWSR/AIM:067398. March 20, 2018.

U.S. Department of the Interior, U.S. Fish and Wildlife Service, and U.S. Department of Commerce, U.S. Census Bureau. 2016. 2016 National Survey of Fishing, Hunting, and Wildlife-Associated Recreation.

U.S. Forest Service. 2017. 2018 Budget Overview. https:/www.fs.fed.us/sites/default/files/ 


\section{usfs-fy18-budget-overview.pdf.}

U.S. Government Accountability Office (GAO). 2016. National Park Service: Process Exists for Prioritizing Asset Maintenance Decisions, But Evaluation Could Improve Efforts. Report to Congressional Requesters, December, GAO-17-136

U.S. National Park Service. 2018. National Park Service Fiscal Year 2018 Budget Justifications. https://www.nps.gov/aboutus/upload/FY-2018-NPS-Greenbook.pdf.

Von Haefen, Roger H., and Frank Lupi. 2021. "How Does Congestion Affect the Evaluation of Recreational Gate Fees? An Application to Gulf Coast Beaches." Land Economics, this issue.

Walls, Margaret. 2013. Paying for State Parks: Evaluating Alternative Approaches for the 21st Century, Resources for the Future Report, January.

Walls, Margaret, and Matthew Aschenfarb. 2021. "Efficiency and Equity of an Outdoor Recreation Equipment Tax to Fund Public Lands." Land Economics, this issue.

Williams, Steve. 2010. "Wellspring of Wildlife Funding: How Hunter and Angler Dollars Fuel Wildlife Conservation." The Wildlife Professional (Fall): 35-38.

Willig, Robert D. 1978. "Incremental Consumer's Surplus and Hedonic Price Adjustment." Journal of Economic Theory 17(2): 227-53. 
Table 1. Estimates of the Willingness-to-Pay-Neutral Scaling Factor.

\begin{tabular}{|c|c|c|c|c|c|c|}
\hline Study & & & & & & \\
\hline $\begin{array}{l}\text { Parsons et al } \\
\text { (2018) 2002\$ }\end{array}$ & $\begin{array}{l}\text { Average } \\
\text { Loss Per } \\
\text { User by } \\
\text { Park }\end{array}$ & $\begin{array}{l}\text { Share of In- } \\
\text { come }\end{array}$ & $\begin{array}{l}\text { Camping } \\
\text { Expendi- } \\
\text { tures }\end{array}$ & $\begin{array}{l}\text { Hiking ex- } \\
\text { penditures }\end{array}$ & Mountain & $\begin{array}{l}\text { Wildlife } \\
\text { Viewing } \\
\text { Expenses }\end{array}$ \\
\hline $\begin{array}{l}\text { Gear Ex- } \\
\text { penditure } \\
\text { Share of In- } \\
\text { come }\end{array}$ & & & 0.0044 & 0.0030 & 0.0030 & 0.0100 \\
\hline \multicolumn{7}{|l|}{$\begin{array}{l}\text { Southwest } \\
\text { Parks }\end{array}$} \\
\hline Arches & 185 & 0.0136 & 3.109 & 4.481 & 2.359 & 1.355 \\
\hline Bryce & 174 & 0.0135 & 3.075 & 4.433 & 2.334 & 1.340 \\
\hline Canyonlands & 150 & 0.0131 & 3.001 & 4.326 & 2.277 & 1.308 \\
\hline $\begin{array}{c}\text { Grand Can- } \\
\text { yon }\end{array}$ & 227 & 0.0142 & 3.239 & 4.668 & 2.458 & 1.411 \\
\hline Mesa Verde & 165 & 0.0133 & 3.047 & 4.392 & 2.313 & 1.328 \\
\hline $\begin{array}{c}\text { Petrified For- } \\
\text { est }\end{array}$ & 141 & 0.0130 & 2.973 & 4.286 & 2.256 & 1.296 \\
\hline Zion & 186 & 0.0136 & 3.112 & 4.486 & 2.362 & 1.356 \\
\hline $\begin{array}{l}\text { Household } \\
\text { Income }\end{array}$ & 74050 & & & & & 79000 \\
\hline \multicolumn{7}{|c|}{ Haefele, Loomis and Bilmas (2020) 2014\$ } \\
\hline $\begin{array}{c}\text { Avoiding } \\
\text { Sale of in } \\
\text { Nature Based } \\
\text { National } \\
\text { Parks }\end{array}$ & 1113 & 0.0177 & 4.039 & 5.822 & 3.065 & 1.760 \\
\hline $\begin{array}{c}\text { Avoiding } \\
\text { Sale of in } \\
\text { Water Based } \\
\text { National } \\
\text { Parks }\end{array}$ & 978 & 0.0155 & 3.549 & 5.116 & 2.693 & 1.546 \\
\hline $\begin{array}{l}\text { All National } \\
\text { Parks }\end{array}$ & 2967 & 0.0471 & 10.768 & 15.520 & 8.171 & 4.692 \\
\hline $\begin{array}{l}\text { Household } \\
\text { Income }\end{array}$ & 63000 & & & & & 79000 \\
\hline
\end{tabular}


Figure 1. Increased Value of the Private Good Caused by Improved Public Good

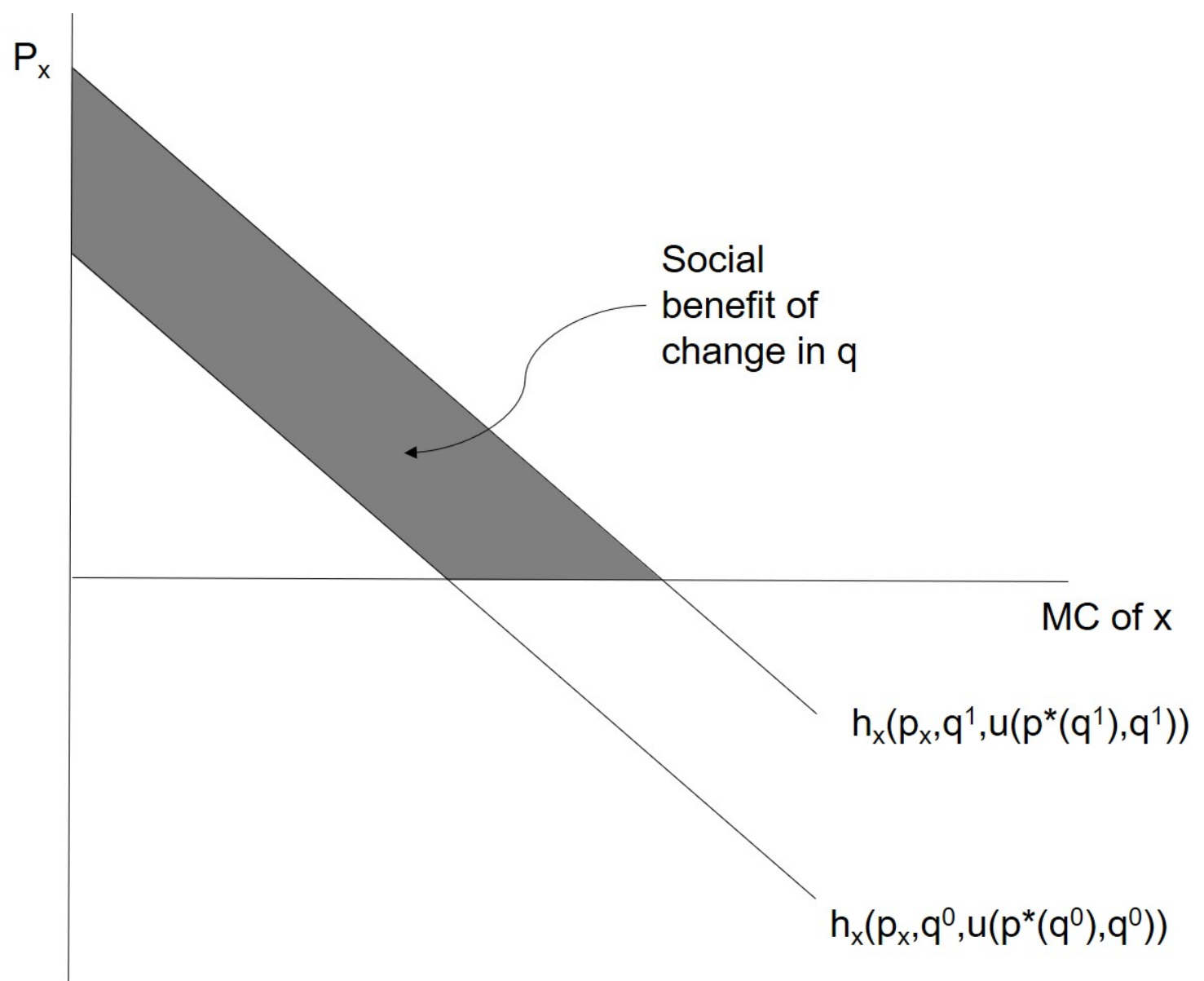

Private Weak Complement (x) 
Figure 2. Value of the Improvement in the Public Good

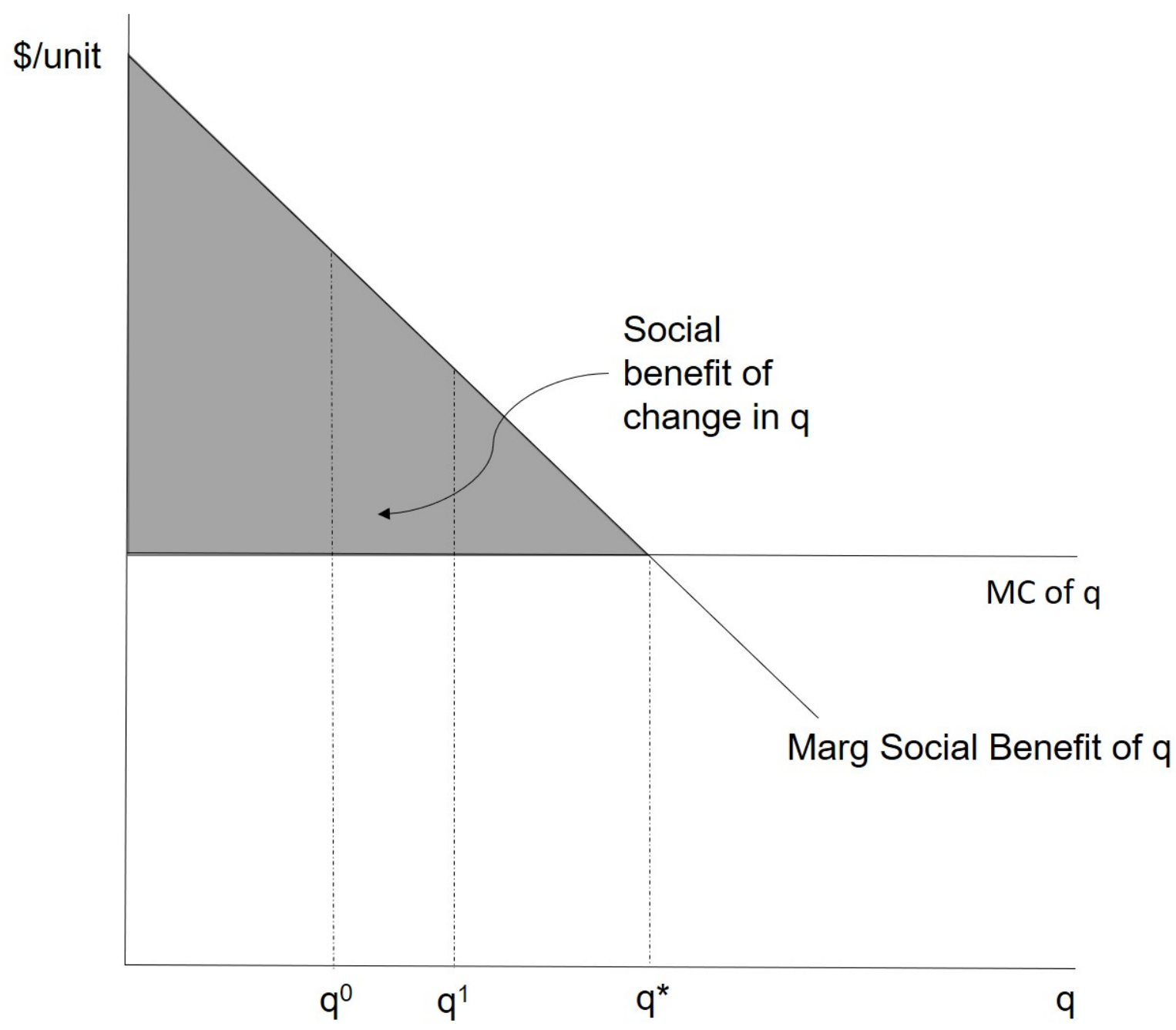


Figure 3: Fanned Indifference Curves and Weak Complementarity

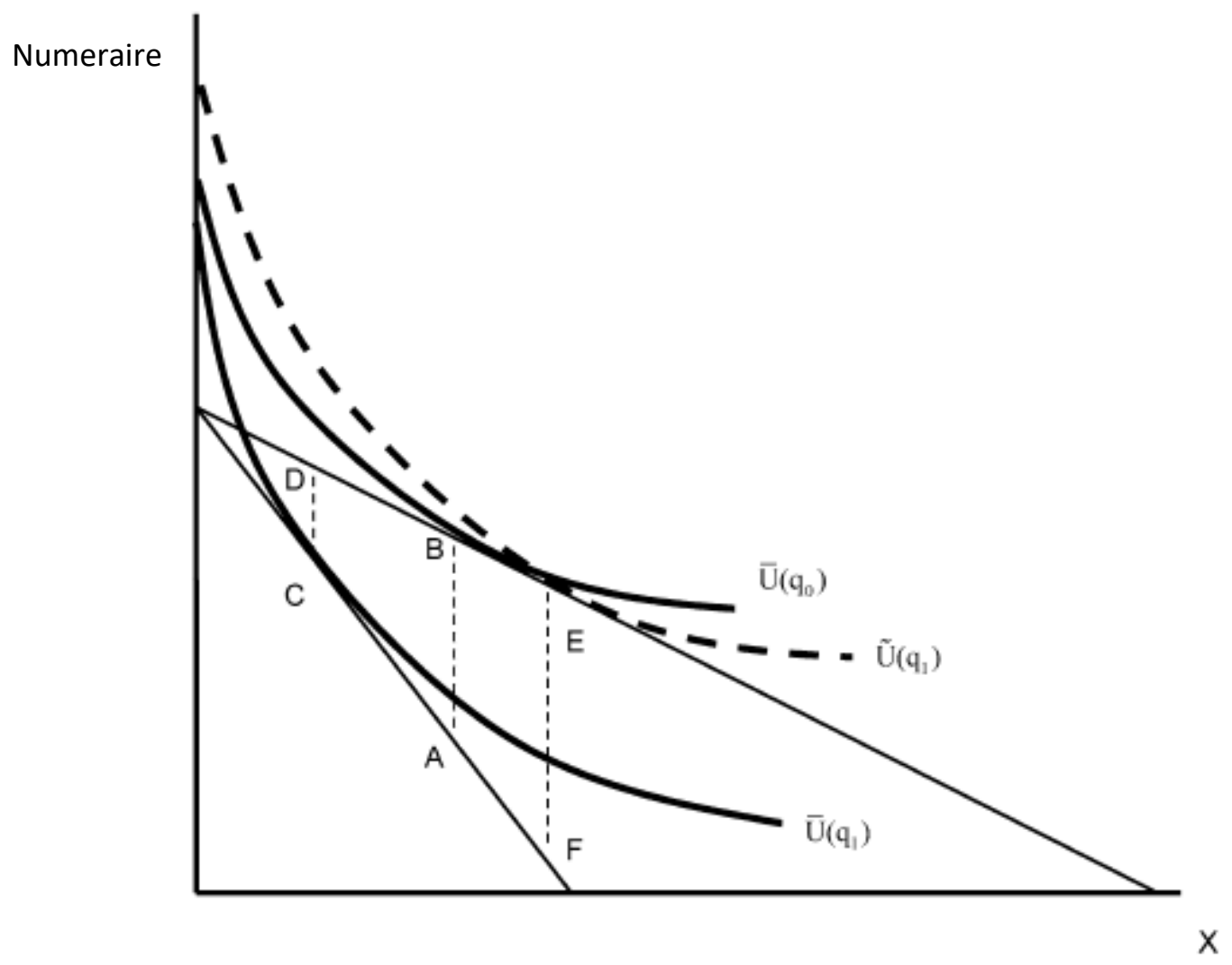


Figure 4. Joint Effects of Gear Tax and Quality Change.

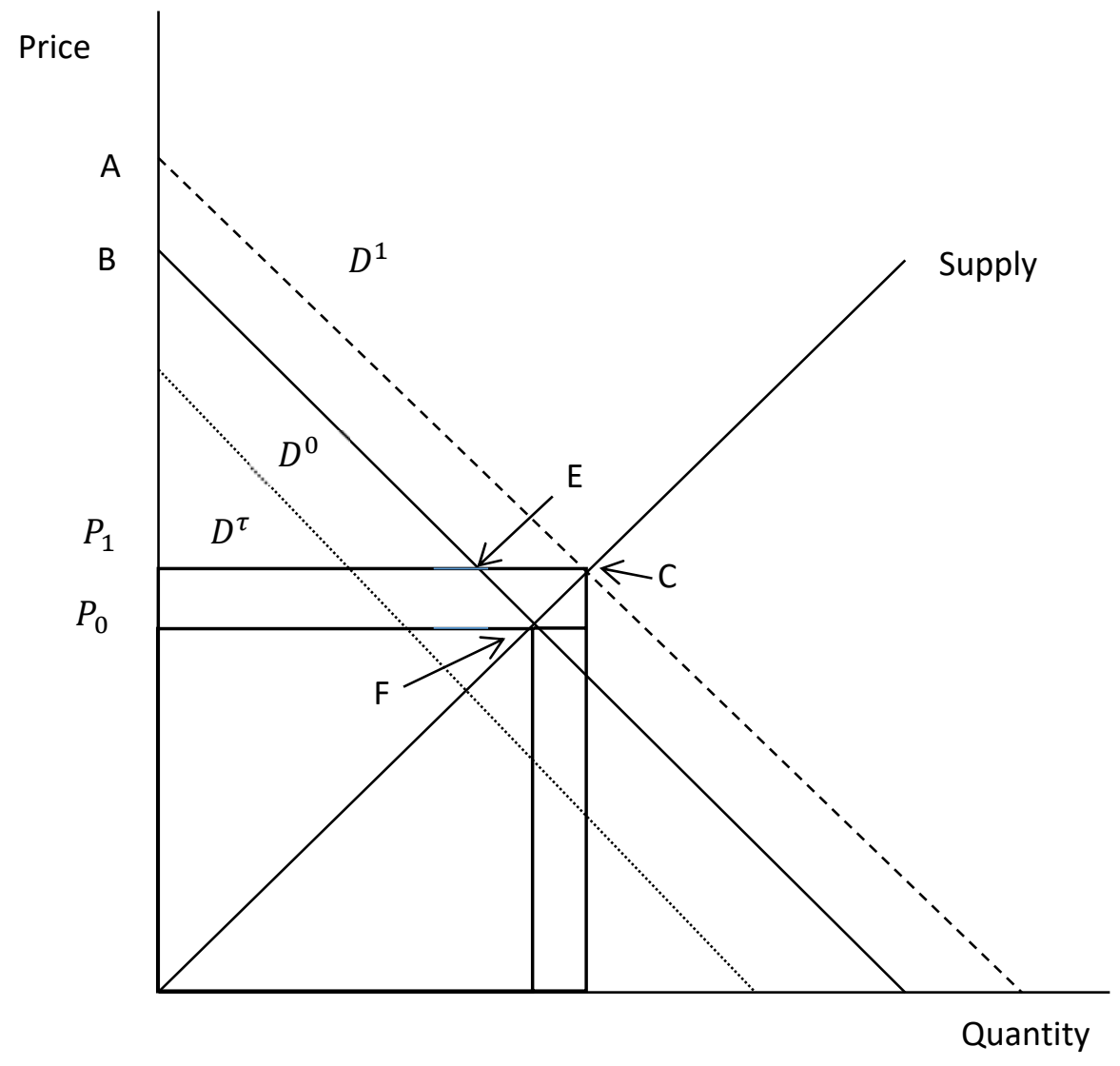




\section{End Notes}

${ }^{1}$ A new method for estimating deferred maintenance has been developed by the National Park Service to
provide more timely updates. However, data issues have delayed release of new estimates (private corre-
spondence between V.K. Smith and C. Notzon, 2/8/2021).
${ }^{2}$ In February 2019, Congress permanently re-authorized the Land and Water Conservation Fund (LWCF) at a level of $\$ 900$ million. The LWCF uses annual revenues from offshore oil and gas leases on federal lands for federal land and water acquisitions. However, in November of that year the Department of Interior under Secretarial Order 3388 imposed new restrictions on the availability of LWCF funding. Recently, under Secretarial Order 3396, the restrictions were rescinded. Given simultaneous restrictions on oil and gas leasing, it is not clear whether, taken together, these actions would limit funding for the LWCF.

${ }^{3}$ Data compiled from NPS (2018), USFS (2017), and CRS (2015). We use 2017 estimates from the 2018 budget requests from the NPS $(\$ 257 \mathrm{~m})$ and NFS $(\$ 65 \mathrm{~m})$ respectively, plus an estimate from CRS (2015) that these two agencies account for $92 \%$ of the total. The authorization for charging these fees expires in September 2020. See Fretwell (1999) and CRS (2015) for overviews of the program.

${ }^{4}$ These laws raise $\$ 1.1 \mathrm{~B}$ per year from an $11 \%$ ad valorem tax on guns, bows, and ammunition and a $10 \%$ tax on fishing gear and boat fuel. See Williams (2010) for an overview of these programs and US DOI $(2018 \mathrm{a}, \mathrm{b})$ for recent dollar figures. A similar proposal for a gear tax was floated during the Reagan administration, when it was sometimes referred to as the "bird seed tax" (Loomis and Olson [1985]).

${ }^{5}$ The benefit approach has been a textbook principle in public finance since Musgrave's (1959) discussion. It had its full realization in Lindahl's voluntary exchange logic and the associated individual pricing of public goods.

${ }^{6}$ In another but related context, Faias and Moreno-Garcia (2019) consider the private provision of public goods when individuals decide both the private contribution as well as their own level of utilization, which may differ among individuals. Policies that affect the utilization of the public good can influence incentives for private provision of the public good positively or negatively depending upon the complementarity or substitutability of the services underlying use and nonuse values.

${ }^{7}$ Thus, Heal (2003) shows that price discrimination is generally required for a firm to have the full incentive to make the investment. As Kotchen (2013) notes, there is a connection between this framework and Lindahl (1919 [1958]) pricing, in which each household pays its marginal value for the public good. Here, that household-specific price for the public good is captured in the market for the weak complement.

${ }^{8}$ Arguments relying on weak complementarity have also been used to construct price indexes that allow for new private goods as well as to adjust for quality attributes of existing private goods (see Bresnahan and Gordon (1997), especially pp 8-14). Their discussion of a supply shift is a simpler version of our analysis in Section 4. Somewhat surprisingly, this literature fails to recognize the link to Mäler's results and its use in the literature on revealed preference approaches to nonmarket valuation.

${ }^{9}$ This assumption is largely for simplicity and our results could be generalized to account for such costs. Rivalry would imply there are opportunity costs for serving additional trips to a site. For example, congestion is a concern in some contexts (von Haefen and Lupi, this issue). Additionally, trips might require additional facilities maintenance. Unfortunately, data on maintenance is available only at an aggregate level (GAO [2016], Table 2). Using ten years of data by budget category and fund sources, we found that maintenance for facility operations, routine services using recreation fees, and for the Federal Lands transportation components were all significantly related to visitation levels.

${ }^{10}$ The feasibility of realizing $\Delta q$ depends on the tax base, including the trips per household $x$ and the extent of the market $N$, and the cost of $q$. Our analysis leading to Expression (6) does not discuss the point of 
evaluation for the partial derivatives leading to $\frac{\pi}{x} \Delta q$. At the travel costs without the added fee, $x$ corresponds to initial average number of trips per user. With the fee and $\Delta q$ the new equilibrium number of trips will be different. Thus, in principle, there is also the second-order consideration of the feedback effect of the tax and quality change on the revenue. By using first-order effects, our analysis ignores this feedback. However, it can never overturn our test. If the fee and the reinvested revenue assessed on the baseline number of trips jointly increase the number of trips (our condition for increased welfare), then that change can only increase the associated $\Delta q$, thus further increasing welfare. If, on the other hand, the joint effect of the fee and the quality change decrease the number of trips (our condition for reduced welfare), then that change can only decrease the associated $\Delta q$ through the eroded tax base, thus further decreasing welfare. Either way, our welfare bounds still hold.

${ }^{11}$ Note that if $\delta=0$ we would have $1-J /(J+1)>0$ in brackets; but the term in brackets is increasing in $\delta$.

${ }^{12}$ Of course, whether the test is met is an empirical question. Walls and Ashenfarb (this issue) estimates the demand for gear is relatively elastic, although at reasonable tax levels the excess burden is low. However, she does not consider the complementarity between gear and the investment funded by the dedicated tax.

${ }^{13}$ See Phaneuf and Smith (2005) and Lupi, Phaneuf, and von Haefen (2020) for reviews of this literature.

${ }^{14}$ The estimate for median income we used was $\$ 58,988$ in 2016 dollars. See https://fred.stlouisfed.org.

${ }^{15}$ The report did indicate expenditures on wildlife viewing were elicited but did not report them, presumably because the percentage participation was small.

${ }^{16}$ A second choice question explained as independent was asked about different cutbacks in park programs.

${ }^{17}$ The NPS has moved to a parametric assessment methodology for computing deferred maintenance. This approach uses the condition of major components of each asset and recovers an implicit estimate of measure of deferred maintenance based on the asset's current replacement value (personal discussion between Smith and Charles Notzon of the NPS, 2/8/2021). 


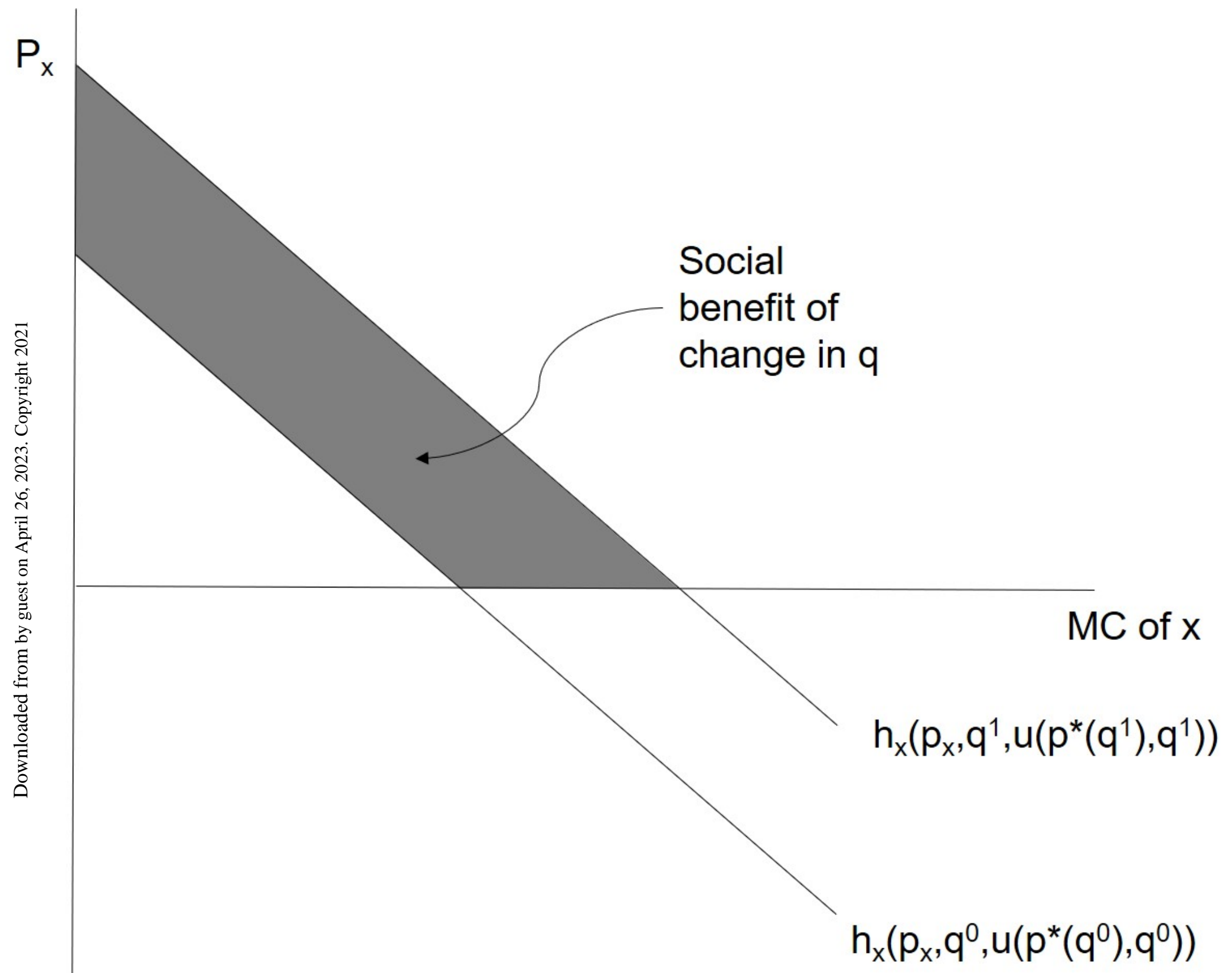

Private Weak Complement (x) 


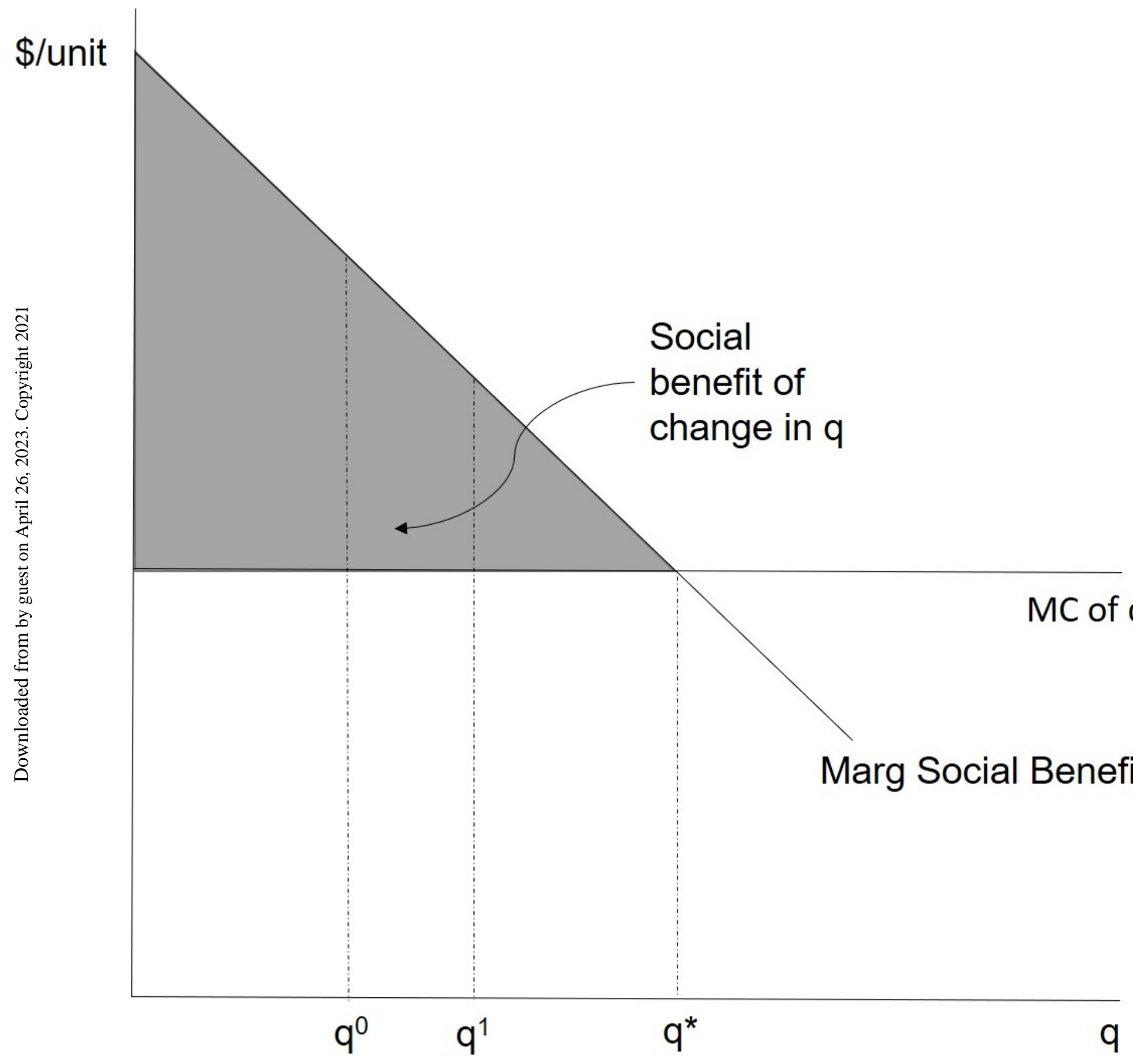




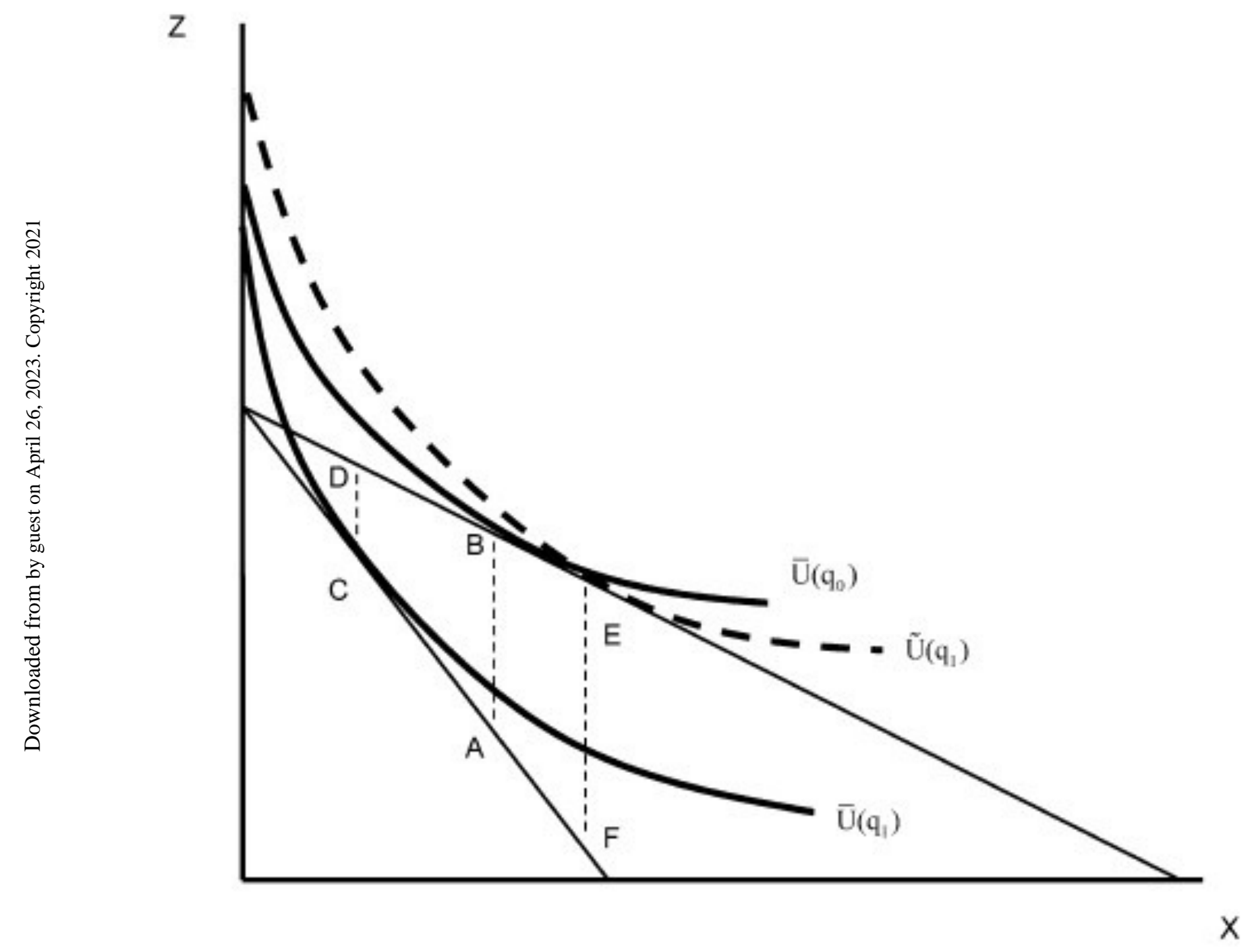




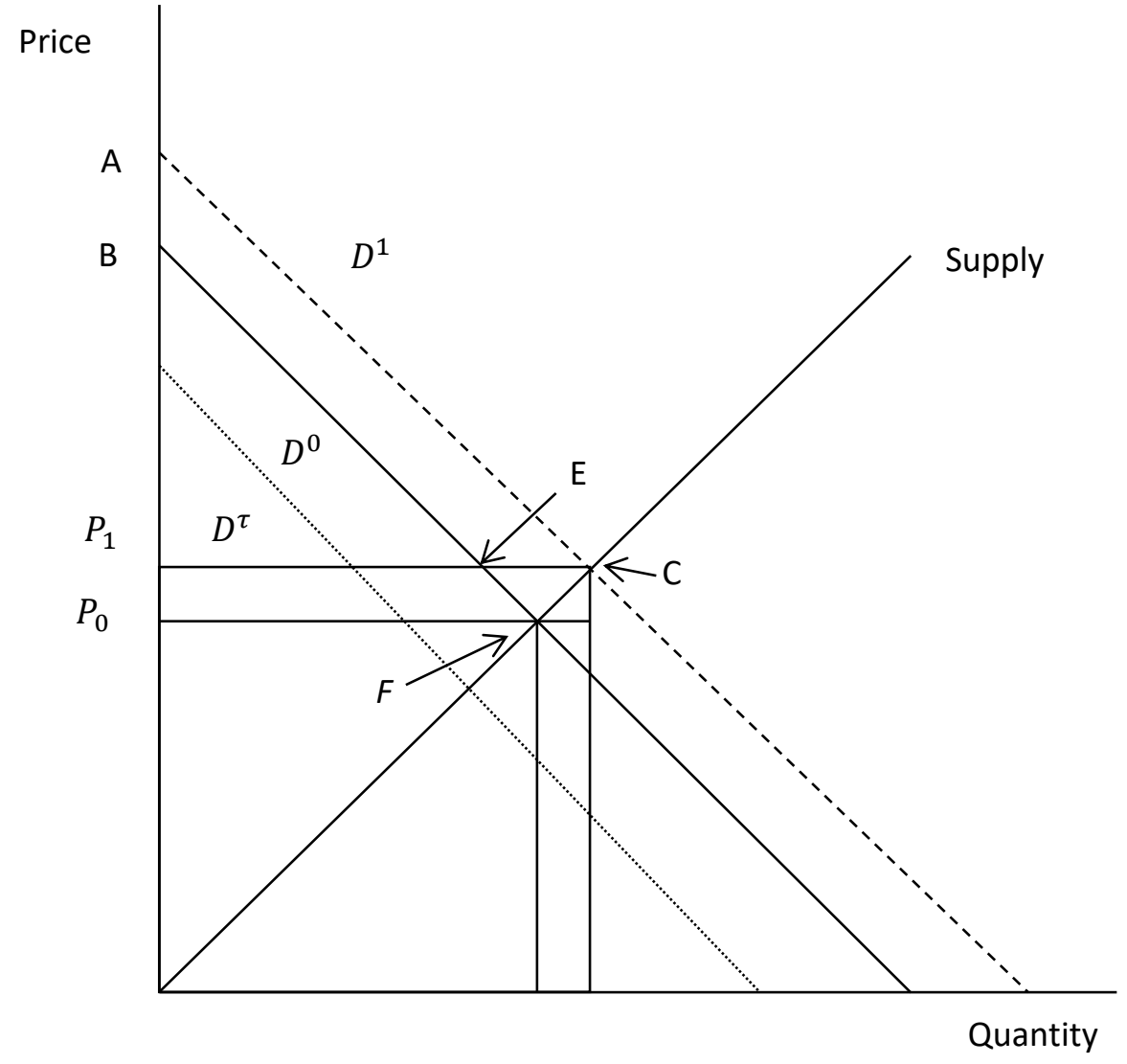

